\title{
Research on the Relationship between Human Capital and Regional Economic Growth
}

\author{
Fang Yang \\ Weinan Normal University, Weinan, Shaanxi, 714000
}

Keywords: Human capital; regional economy; growth; industrial structure

\begin{abstract}
Since the reform and opening up, China's economy has undergone rapid growth in the past 30 years. As the demographic dividend has receded and the capital output rate has dropped, the Chinese economy has entered a relatively stable new normal. In this environment, we must improve the quality of the dynamical elements of economic growth to better adapt to the current development situation, and the important factor of the economic growth of the labor force should also continue to mention its own quality of development and better promote the mode of economic growth in our country Upgrade conversion. An important feature in the process of economic development is the transformation of traditional industries into modern industries. Especially after the economic development has entered a new normal, the Chinese economy is in a critical period of industrial upgrading. Upgrading and transformation of the industrial structure will in turn lead to the growth of human capital and other economic growth factors to upgrade, optimize, and therefore will have a direct impact on the economic growth of human capital. The article mainly discusses the relationship between human capital and regional economic growth.
\end{abstract}

\section{Introduction}

As an intangible intangible capital, human capital structure reflects the following characteristics:

First, externalities. The structural state of human capital is indirectly manifested through economic activities, which shows obvious economic externalities and spillover effects. Second, diversity. There are many ways to divide human capital structure, such as allocation based on division of labor, allocation of investment subject or human capital, investment efficiency, etc. The different division modes make human capital embody the diversification of structure. Third, adjustability. As an economic factor, the human capital formed by the structure of human investment is an objective factor. Many economic factors and non-economic factors will restrict the formation of its structure and level. Related factors Will have an impact on its structure and function, such as investor preferences, policy environment, cultural atmosphere, etc., and can adjust the structure of human capital to achieve the best condition. Fourth, unity. The integrity of human capital structure and the function of the entire economic system will be affected by any weakened or absent structure. The various factors that affect economic development in the entire economic system do not exist in isolation but exist in some way and interact with each other. Therefore, in order to realize the unification of human capital structure, all kinds of structural forms must be organically integrated together. Fifth, population attributes. Human beings are the only carriers of human capital, and this feature determines the demographic attributes of human capital. Therefore, when analyzing the related problems of human capital structure, we should not only analyze from an individual perspective, but also focus on the human resources of a country or region The conditions constructed by capital are based on the total amount of human capital or from the perspective of socio-economic development and regional population. Sixth, dynamic. With the development of time and economic environment, the structure of human capital will also exhibit dynamic characteristics. Therefore, the study of human capital structure not only analyzes the static state within a specific time, but also analyzes the time series from its dynamic changing law So as to have a deeper understanding of the laws governing the development of human capital structure so as to optimize the structure and function of human capital more effectively and to better grasp and adjust the changes of the mechanism. Finally, the relative stability. Although the human capital 
structure as a whole shows the characteristics of dynamism, it can enter into a relatively stable state under the influence of quantitative change and qualitative change of timeliness constraints within a specific time. Therefore, the inherent variation of the human capital structure can be analyzed quantitatively Understand.

\section{The relationship between human capital and economic growth}

In almost every country, the economic development embodies a disequilibrium point of view. There are also big differences in economic development in different regions. The development of regional economy should be based on abundant natural resources and superior natural conditions. However, the quality and level of economic foundation will directly affect the level of economic growth in the region. In the light of the close relationship between man and nature, The important role of growth is highlighted. The traditional factors of production such as land, capital and labor force are important preconditions in the process of economic development. However, the continuous positive role of human capital is an important carrier to give full play to the role of these factors of production. In particular, human capital is professionally trained through education and training After that, it is an important impetus for maintaining a long-term sustained regional economic growth. In different regions, even if they have the same natural conditions, differences in their internal and external structures of human capital may also lead to differences in relative superiority among the regions in product production. Compared with other structures, the specialization of regional production led human capital to continuously expand the number of labor force and improve the quality of labor force. Finally, the structure of human capital shows obvious comparative advantages over other factors, and this comparative advantage is more relative to regional innovation ability an important factor of advantage. It can be seen from this that human capital is an important factor in promoting regional economic growth. It can promote regional economy to a steady and steady growth by replacing material capital with material capital.

Different levels of human capital, so the investment in human capital in a certain range of options, so a long time different regions formed a different structure of human capital stock. If we want to examine the coordination and balance of human capital structure in a certain region, we must measure and evaluate the stock of different human capital in the region through certain measurement tools and indicators. The types of human capital are different, and their investment choices vary. The end result is that there are differences in the structure of human capital stock formed in different regions over a long period of time. Therefore, it is necessary to distinguish the human capital structure of regional human resources in order to better explore human capital The role of regional economic growth. Based on the proportional structure of professional human capital and entrepreneurial human capital, the paper examines the status of regional human capital. The combination of the levels of the two human capital levels in different regions can provide four kinds of human capital structure patterns for regional development. One is a double-high human capital model, that is, the human capital stock required by both regional entrepreneurial human capital and professional human capital growth is relatively high; the corresponding double high-type is double low human capital model, that is, The second is the richness of human capital of entrepreneurs, that is, the stock of human capital of entrepreneurs is high, the stock of professional human capital is low, and the human capital of entrepreneurs is more abundant; the fourth is the correspondence between the two types of human capital, Of professional human capital is rich, and there is a high stock of professional human capital in the region. From the analysis, we can see that Shuanggao is the most ideal structural state among the four human capital stock structure models. The three structural models of the remaining have optimal policy choices for the contribution to regional economic growth. Therefore, the development model of regional economy should be based on double High-profile structural model as the main objective in order to maintain regional economic growth.

Regional economic development takes the change of the regional economic structure as the main manifestation. An important intrinsic sign of the regional economic development level is its economic structure. Optimizing and upgrading the regional economic structure are the important 
sources of promoting the regional economic development. The whole process takes the The upgrading of the industrial structure as the core. However, in the process of actual development, technological factors, institutional factors, supply factors, demand factors and social factors all have a direct impact on the adjustment of industrial structure. In different historical stages of economic development, different social division of labor and development of productive forces Different periods, the impact on the industrial structure there is a big difference. For example, in the industrial economy, the adjustment of regional industrial structure highlights natural endowments. Therefore, the industrial structure is mainly adjusted according to the distribution of natural resources. In the era of knowledge-based economy, the role of natural endowments is weakened. Human capital plays an important role in the adjustment of regional industrial structure. Therefore, the influence of human capital structure and stock on regional industrial structure and industrial technological structure is even more prominent. It is precisely because the adjustment of industrial structure in a region is largely based on the stock of human capital and the structural conditions. Therefore, the advance of the adjustment of human capital structure will bring about a qualitative leap in the development of regional economy. Thus, human resources Capital structure and industrial structure is a positive relationship between.

\section{Optimize human capital structure and promote regional economic growth strategy}

First of all, we should establish an efficient, coordinated and open technological innovation system and improve the capability of technological innovation in the region. Efficient, open and collaborative technological innovation system is a necessary condition to improve the carrying capacity of human capital in the region. Therefore, government departments should enhance awareness of cultivating scientific and technological innovation ability in the region, give full play to their leading role and attract advanced enterprises at home and abroad, R \& D institutions and research institutes set up branches in the region to encourage the development of a combination of production, study and research, promote the formation of complementary advantages between enterprise capital and scientific research, jointly develop new products, enhance the transformation capacity and transformation efficiency of scientific research achievements, Innovation forms the new advantage of regional economic growth. Second, change the concept of investment, prompting the optimization of human capital and material capital. Adhering to the optimization and combination of material capital and human capital is an important way to enhance the carrying capacity of regional human capital, reasonably maintain the proportional relationship between the investment of physical capital and human capital, and give full play to its utilization efficiency by aiming at the coordinated development of the two. In order to effectively utilize physical capital, optimize resource allocation and increase production efficiency, we should increase investment in human capital in the region so as to increase the accumulation of human capital and maintain a sustained and steady regional economic development. Finally, to promote the merger of education and industrial system, to promote the transformation and upgrading of labor employment structure. To achieve the merger of education and industrial system and to realize the transformation of labor employment structure, we must first reform the education and vocational education system and its system, and vigorously develop secondary and higher vocational education so as to cultivate a large number of applied talents. At the same time, it is necessary to carry out large-scale and modern agricultural production, vigorously develop modern industries, transform traditional service industries, speed up the development of emerging service industries with great market potential, create more jobs and promote the labor force to secondary and tertiary industries Transfer.

\section{Conclusion}

Human capital itself has obvious structural characteristics. Therefore, analyzing its functions based on structural perspective is one of the basic ways to recognize its important role in economic development. According to a large number of research theories, the relationship between human capital structure and regional economic development is regulable, while the study of human capital 
and its structural factors is an important part of regulating economic relations in the region. In the process of actual economic development, we must abide by the regulation and control mechanism of human capital structure and regional economic development, apply scientific regulation and control mode, formulate feasible maneuvering human capital policies in order to promote the coordinated development of regional economy.

\section{References}

[1] Zhou Wenxia. A Meta-Analysis on the Occupational Success of Chinese Employees Affected by Human Capital, Social Capital and Psychological Capital [J]. Acta Psychologica Sinica, 2015 (02): 251-263.

[2] Li Haizheng, Jia Na, Zhang Xiaobei. Regional Distribution and Development Trend of Human Capital in China [J]. Journal of Economic Research, 2013 (07): 49-62.

[3] Li Dehuang, Xia Enjun. Effects of human capital on China's economic growth: A study based on the extended Solow model [J]. Chinese Journal of Population, Resources and Environment, 2013 (08): 100-106.

[4] Fang Fuqian, Zhu Lingmin. Population structure, human capital structure and economic growth [J]. Economic Theory and Business Management, 2013 (08): 5-16.

[5] Gao Yuandong, Hua Yongjun. An Empirical Analysis of the Effect of Heterogenous Human Capital on Economic Growth [J]. Economic Science, 2017 (01): 39-50.

[6] Meng Da-hu, Su Li-feng, Li Lu. Employment and Employment Quality of Human Capital and College Students - An Empirical Analysis Based on Questionnaire Data [J]. Population \& Economics, 2017 (03): 19-26.

[7] Zhang Guoqiang, Wen Jun, Tang Xiangjun. China's human capital, human capital structure and upgrading of industrial structure [J]. China Population, Resources and Environment, 2016 (10): 138-146. 